\title{
Comparison of the actual and theoretical energy use in nZEB renovations of multi-family buildings using in situ monitoring
}

\author{
Stijn Van de Putte ${ }^{1, *}$, Wolf Bracke ${ }^{1}$, Marc Delghust ${ }^{1}$, Marijke Steeman ${ }^{1}$ and Arnold Janssens ${ }^{1}$ \\ ${ }^{1}$ Department of Architecture and Urban Planning, Faculty of Engineering and Architecture, Ghent University, \\ SintPietersnieuwstraat 41, 9000 Ghent, Belgium
}

\begin{abstract}
Often there is a significant difference between the actually measured and theoretically calculated energy use. The deviation between the two can be a result of errors in design, construction or commissioning, due to the technical performance of building components and installations that don't meet the design requirements. But equally, incorrect assumptions in the calculation can largely affect the results, for example the user influence that is simulated in a different way. This paper presents the analysis of data from an on-site monitoring system of two case study multi-family buildings that were deeply refurbished. It points out that the calculated energy use for space heating was largely underestimated, while there was an overestimation of the energy use for domestic hot water. The high indoor temperature and the low occupancy of the apartments were identified as the key parameters to explain this striking difference between the theoretical design and the actual situation.
\end{abstract}

\section{Introduction}

Since the building sector is responsible for $31 \%$ of the total Flemish non-ETS greenhouse gas emissions (with a $75 \%$ share by the residential buildings) [1], the Flemish government focuses a lot on the construction sector in the implementation of their climate policy. Given that the majority of the building park consists of old, uninsulated dwellings, renovation plays an essential role in this. $78 \%$ of the Flemish buildings are built before 1992; for apartment buildings specifically this is $64 \%$ [2]. To reach the target for the realisation of a nearly energyneutral building stock by 2050 , the current renovation rate of less than $1 \%$ must substantially be increased and the executed renovations must be more and more indepth. To improve knowledge about large-scale renovations, the policy facilitates several research projects.

In the framework of the Flemish Living Lab Projects [3], a multifamily building owned by a social housing company underwent a deep renovation between 2016-2019. This building block, abbreviated DH IV, is situated at the Drie Hofsteden site in the city of Courtrai (Belgium) and dates from the early 1970's. It counted 11 floors with 127 similar apartments in poor condition. An improvement in living quality was necessary.

This research project follows the European ECO-Life project [4], completed in 2016, during which a similar apartment block on the same site, called DH V, was renovated. The building had the same number of floors, but was slightly smaller, consisting of 110 apartments. After renovation these buildings had 118 and 109 apartments respectively. This study aims to evaluate the actual energy performance of both buildings and compare them with the theoretical design calculations.

\section{Case study}

\subsection{Building envelope}

Because of the resemblance between both building blocks, the refurbishment strategies were analogous: during the construction works, phased over time per vertical circulation block, the building façades were completely dismantled until only the structural support remained. The main characteristics of both case studies are listed in Table 1. In contrast to the slightly older building of DH IV, the cavity walls of DH V were insulated with some mineral wool. The new building envelopes are similar: most façades are executed with an ETICS system, including $27 \mathrm{~cm}$ of EPS, combined with aluminium window frames and triple glazing. The achieved airtightness $\mathrm{n}_{50}$ is $0,68 \mathrm{~h}^{-1}$ for DH IV and $1,63 \mathrm{~h}^{-1}$ for DH V.

However, their energy performance ambitions were somewhat different. The objective of the refurbishment of $\mathrm{DH} \mathrm{V}$ was to perform twice as good as the regulations in force at that moment in Flanders, guided by the passive house standards, i.e. a net heating energy demand of $15 \mathrm{kWh} /\left(\mathrm{m}^{2} . \mathrm{a}\right)$. The objective for DH IV was to transform the building block to a nearly zero energy building (nZEB). In Flanders, this theoretical concept is defined as the EPBD-requirements for newly-built buildings from 2021. For a residential building this means an E-level of E30 or lower. This E-level is a dimensionless indicator for the maximum theoretical primary energy use of a building, in comparison with a reference value. Because of this nZEB-ambition for DH IV the E-levels of the different apartments are less varying and lower than for DH V (Table 1).

\footnotetext{
* Corresponding author: stijn.vandeputte@ugent.be
} 


\subsection{HVAC}

Originally the apartments of DH V had an individual electrical heating system. This was a considerable advantage for the phased construction organisation, in contrast to DH IV where there was a collective hydronic distribution system both for space heating (SH) as for domestic hot water (DHW). The refurbishment provided in both building blocks a collective hydronic heating system, combined for space heating and domestic hot water. Every dwelling's heating and DHW system receives heat from the primary collective circuit via a substation containing a heat exchanger. In DH IV and the first core of $\mathrm{DH} \mathrm{V}$, the energy generation from the gas condensing boilers is supplemented with a share of renewable energy from solar thermal collectors on site.

In order to reduce the heat losses by ventilation a collective balanced mechanical ventilation with heat recovery is installed in both building blocks. Only the dwellings of the first phase of DH V are equipped with heating coils for the preheating of the supply air to avoid draught. Though, these were no longer installed afterwards. There is no cooling installation.

\subsection{Monitoring plan}

An extensive monitoring plan was implemented in both building blocks. Table 2 shows the monitored parameters that are most relevant for this study, specifying their resolution and frequency. All apartments have a standard monitoring, consisting of a calorimeter that logs the total heat use of the dwelling. This meter is essential for the social housing company in order to be able to rightfully bill the energy costs to every tenant. Within the framework of the research projects, all apartments of DH IV and of the first core of DH V are also equipped with a temperature sensor in the living room. Unfortunately, at the time of this analysis, the storage capacity of temperature data was insufficient to provide relevant data series.

In addition, a few apartments were selected throughout the building for some extra monitoring. In 15 dwellings extra calorimeters were installed, in addition to those metering the total heat use, in order to better map the energy use for SH and DHW.

Solely apartments with a full year of data from September 2018 until August 2019 and that were occupied by the same resident during this period, are included in the further analysis of this case study. For DH V this means 105 out of 109 apartments. For DH IV only 65 out of 118 apartments are taken into account, since the last phase of the refurbishment was only occupied in April 2019.

\section{Methodology}

In order to compare data of different projects, at different periods, with different weather conditions, etc. and to analyse variations in a building's energy use, it is necessary to normalise the data. Since the energy categories of a building are dependent of different variables, it is recommended to first categorize these data.
Table 1. Main renovation characteristics of DH IV and DH V.

\begin{tabular}{|c|c|c|}
\hline & DH IV & DH V \\
\hline Before renovation & $(n=127)$ & $(n=110)$ \\
\hline construction period & $1967-1970$ & $1971-1974$ \\
\hline U-value walls & $2.2 \mathrm{~W} /\left(\mathrm{m}^{2} . \mathrm{K}\right)$ & $0.7 \mathrm{~W} /\left(\mathrm{m}^{2} . \mathrm{K}\right)$ \\
\hline avg. U-value windows & $4.9 \mathrm{~W} /\left(\mathrm{m}^{2} . \mathrm{K}\right)$ & $4.8 \mathrm{~W} /\left(\mathrm{m}^{2} . \mathrm{K}\right)$ \\
\hline After renovation & $(n=118)$ & $(n=109)$ \\
\hline construction period & $2016-2019$ & $2015-2017$ \\
\hline U-value walls & $0.12 \mathrm{~W} /\left(\mathrm{m}^{2} . \mathrm{K}\right)$ & $\begin{array}{c}0.12 \text { and } 0.20 \\
\mathrm{~W} /\left(\mathrm{m}^{2} . \mathrm{K}\right)\end{array}$ \\
\hline avg. U-value windows & $0.85 \mathrm{~W} /\left(\mathrm{m}^{2} . \mathrm{K}\right)$ & $0.85 \mathrm{~W} /\left(\mathrm{m}^{2} . \mathrm{K}\right)$ \\
\hline objective & nZEB & passive \\
\hline $\begin{array}{l}\text { theoretical annual net } \\
\text { energy demand for SH* }\end{array}$ & $\begin{array}{c}0.3 / 2.5 / 12.9 \\
\mathrm{kWh} /\left(\mathrm{m}^{2} . \mathrm{a}\right)\end{array}$ & $\begin{array}{c}1.9 / 8.0 / 31.5 \\
\mathrm{kWh} /\left(\mathrm{m}^{2} . \mathrm{a}\right)\end{array}$ \\
\hline E-level* & $23 / 25 / 29$ & $23 / 38 / 53$ \\
\hline $\begin{array}{r}\text { theoretical primary } \\
\text { energy use* }\end{array}$ & $\begin{array}{c}28.7 / 33.3 / 49.0 \\
\mathrm{kWh} /\left(\mathrm{m}^{2} . \mathrm{a}\right)\end{array}$ & $\begin{array}{c}30.0 / 54.2 / 99.4 \\
\mathrm{kWh} /\left(\mathrm{m}^{2} . \mathrm{a}\right)\end{array}$ \\
\hline
\end{tabular}

Table 2. Resolution and frequency of the monitored parameters in DH IV and DH V.

\begin{tabular}{|r|c|c|}
\cline { 2 - 3 } \multicolumn{1}{c|}{} & DH IV & DH V \\
\hline Start monitoring & $12 / 2017$ & $08 / 2016$ \\
\hline total heat & $\begin{array}{c}1 n=118) \\
\text { every day }\end{array}$ & $\begin{array}{c}1 \mathrm{kWh} \\
\text { every } 30 \mathrm{~min}\end{array}$ \\
\hline Basic monitoring & $(n=118)$ & $(n=34)$ \\
\hline temperature living room & $\begin{array}{c}0,1{ }^{\circ} \mathrm{C} \\
\text { every } 8 \mathrm{~min}\end{array}$ & $\begin{array}{c}0,1{ }^{\circ} \mathrm{C} \\
\text { every } 30 \mathrm{~min}\end{array}$ \\
\hline Detailed monitoring & $(n=12)$ & $(n=3)$ \\
\hline heat for SH & $\begin{array}{c}1 \mathrm{kWh} \\
\text { every day } \\
\text { heat for DHW }\end{array}$ & $\begin{array}{c}1 \mathrm{kWh} \\
\text { every } 30 \text { min }\end{array}$ \\
\hline hery day & $\begin{array}{c}1 \mathrm{kWh} \\
\text { every } 30 \text { min }\end{array}$ \\
\hline temperature bedroom & $\begin{array}{c}0,1{ }^{\circ} \mathrm{C} \\
\text { every } 8 \mathrm{~min}\end{array}$ & $\begin{array}{c}1 \mathrm{kWh} \\
\text { every } 30 \mathrm{~min}\end{array}$ \\
\hline
\end{tabular}

\subsection{Categorisation of energy use data}

Most of the apartments only have a calorimeter that logs the total heat use of the dwelling. Only in the apartments monitored in detail there is energy data available for the different categories: space heating, domestic hot water and, only in DH V, preheating of the supply air. By analysing the ratio of the energy categories in this limited sample, the heat use of all apartments can be categorised. Since only in DH V there is at least one year of data available for the closely monitored apartments, they will act as the main reference for disaggregating the data.

Fig. 1 (a) shows that the monthly energy use for $\mathrm{SH}$ (qheat) strongly varies during the year depending on the outdoor climate and is much larger in comparison to the energy use for DHW ( $\mathrm{q}_{\text {water }}$ ), which is more or less constant all year. The heating coils seemingly don't use any energy. Furthermore, the total energy use $\left(\mathrm{q}_{\mathrm{tot}}\right)$ is in all dwellings somewhat higher than the sum of the previously mentioned categories: this difference can be explained by the heat losses of the substation's heat exchanger between the calorimeters ( $\left.\mathrm{q}_{\text {diff }}\right)$. In the further analysis this residual heat is considered as a, albeit uncontrolled, part of the $\mathrm{SH}$. During summer $\mathrm{q}_{\mathrm{water}}$ is on average around $70 \%$ of the total energy use and the share of qheat is negligibly small (Fig. 1 (b)). 


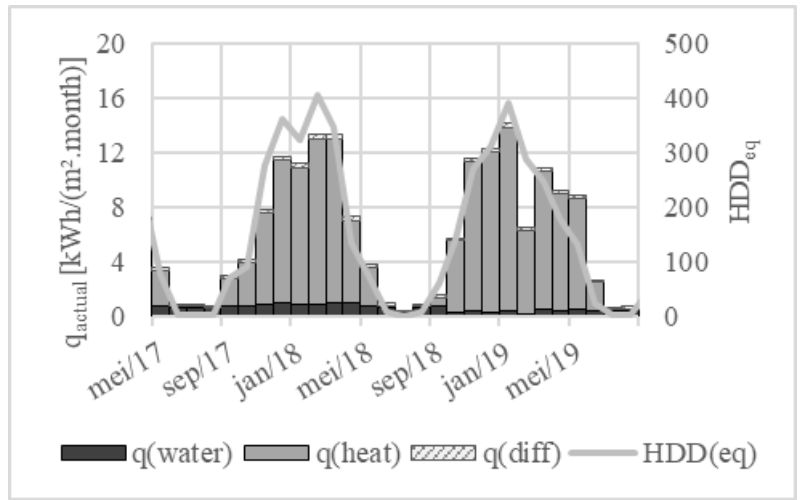

(a)

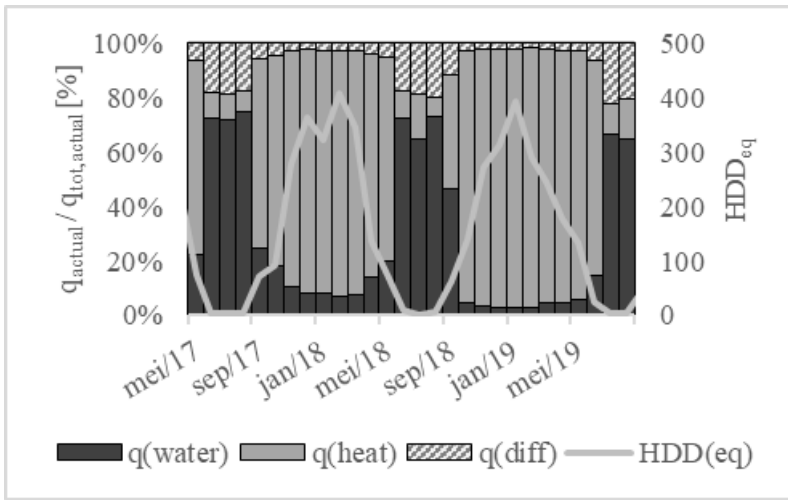

(b)

Fig. 1. Measured energy use for SH and DHW of an apartment in DH V with detailed monitoring: (a) absolute, (b) relative.

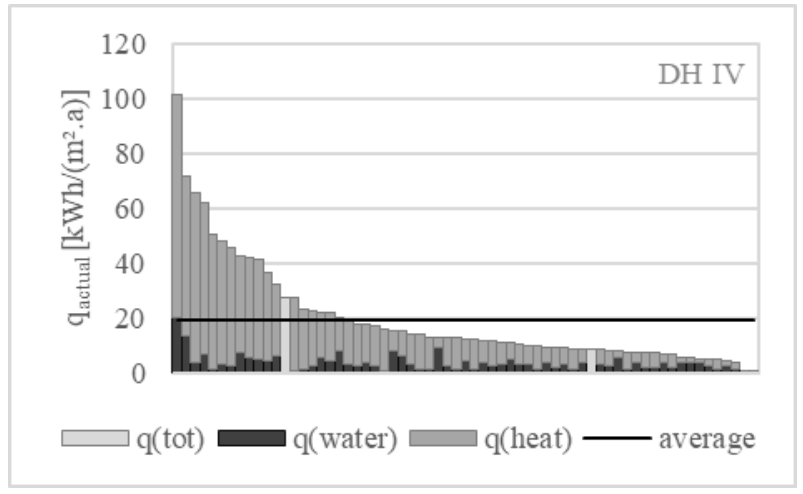

(a)

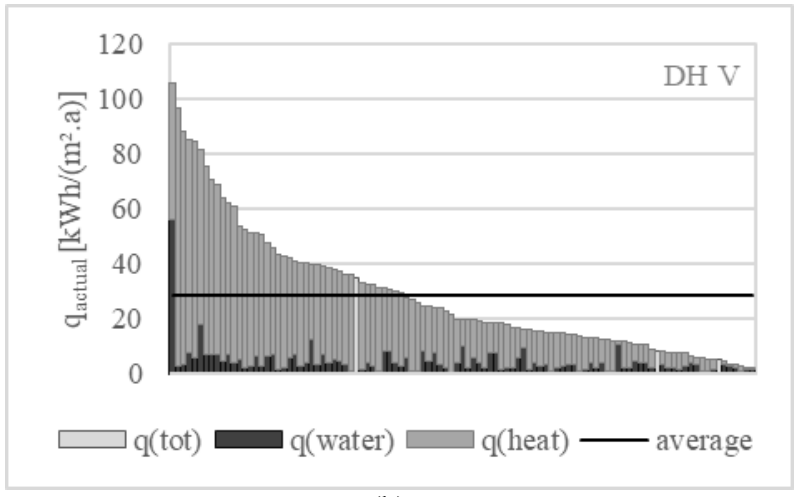

(b)

Fig. 2. Monitored yearly gross energy use for SH and DHW in (a) DH IV and (b) DH V.

To disaggregate the metered energy use of the total sample, $70 \%$ of the energy use in July or August, whichever is the largest (to avoid periods of long term absence), is considered to represent $\mathrm{q}_{\text {water. }}$ A certain variation is taken into account due to the seasonaly varying cold water temperature and use of DHW [5]. The correction factors are adopted from a study based on several apartment buildings in Belgium [6]. The remaining part is considered as $\mathrm{q}_{\text {heat }}$ (including $\mathrm{q}_{\mathrm{diff}}$ ).

Fig. 2 displays the monitored energy use of all dwellings in DH IV and DH V, disaggregated in the heating energy need for SH and DHW. Although the apartments are geometrically similar there is a wide variation in their total gross energy use during one year. Moreover the graph illustrates that in the vast majority of the apartments the annual energy use for DHW is significantly smaller than the share for SH. In DH IV $18,4 \%$ of the total heat is used for DHW; in DH V this is $15,5 \%$.

\subsection{Normalisation of energy use data}

Firstly, the energy use of every dwelling is expressed per unit of gross floor area in order to limit the influence of the size of the dwelling. This way the energy use of the apartments can better be compared with one another. In DH IV the gross floor areas of all apartments are between 91 and $119 \mathrm{~m}^{2}$ (97 $\mathrm{m}^{2}$ on average); in DH V the apartments are somewhat smaller, i.e. between 72 and $108 \mathrm{~m}^{2}\left(83 \mathrm{~m}^{2}\right.$ on average).
As Fig. 1 (a) illustrated, qheat is strongly dependent on the outdoor climate. The seasonal variation of the outside temperature influences the gross heating energy demand. To correct this energy use for $\mathrm{SH}$, the heating degree day (HDD) method is used as a normalisation technique. This method provides a measure of how much and for how long the outside temperature was below a base temperature $\theta_{\mathrm{b}}$. Different variants of this method were analysed. In this study Eq. 1 is used, with an equivalent outside temperature $\theta_{\mathrm{e}, \mathrm{eq}}$ taking into account the exterior temperature of that day and the two previous days (Eq. 2), based on hourly data of a climate station of the Belgian RMI $15 \mathrm{~km}$ away of the case study site. As base temperature $16,5^{\circ} \mathrm{C}$ is used, corresponding with the standard reference for Belgian gas bill correction. In the studied year 2058 HDD were defined. This indicates a milder climate compared to a "normal year" with 2301 HDD, based on climatic data for the period 1986-2015.

$$
\begin{aligned}
& H D D_{e q, m}=\Sigma\left[\max \left(0 ; \theta_{b}-\theta_{e, e q, d}\right)\right] \\
& \text { with : } \theta_{e, e q, d}=0,6 * \theta_{e, d}+0,3 * \theta_{e, d-1}+0,1 * \theta_{e, d-2}
\end{aligned}
$$

Monthly energy use figures are normalised to a representative year using Eq. 3. Because of a rather high outside temperature during some months of the period of analysis, this correction results in normalised figures that are substantially higher than the actual monitored energy use for SH (average increase of 17,5\%).

$q_{\text {heat }, \text { }, \text { norm }}=q_{\text {heat }, m, \text { monitored }} *\left(H D D_{\text {eq,m,norm }} / H D D_{\text {eq, } m}\right)$ 
In absence of sufficient data about the indoor temperature in all apartments, it was not possible to correct the monitored data for the user influence on the indoor climate. Because of the very good thermal insulation and airtightness the heat use is also influenced by variations in internal and solar heat gains [7]. However, the solar irradiation and user behaviour parameters weren't applied in this study.

\section{Theoretical energy use calculation}

\subsection{Net energy use}

The theoretical energy uses were calculated by the architectural office of the project as part of the regulatory energy performance declaration based on as-built input data. The calculations followed the Flemish EPBD methodology [8], which uses a single-zone quasi-steady state approach. These outputs for the net energy demand are used as a basis for the theoretical predictions.

The net heating energy demand $Q_{\text {heat,net }}$ is calculated monthly according to Eq. 4., taking into account heat losses $\mathrm{Q}_{\mathrm{L}}$ through transmission and ventilation and heat gains due to solar radiation $\mathrm{Q}_{\mathrm{s}}$ and internal gains $\mathrm{Q}_{\mathrm{i}}$. The heat loss calculation applies a monthly constant outside temperature $\theta_{\mathrm{e}}$ and a constant indoor temperature of $18^{\circ} \mathrm{C}$ as a daily average for all rooms of the unit (Eq. 5). The solar gains are calculated based on monthly values for the total and diffuse irradiance. The internal heat gains merely depend on the volume of the sector. The calculated net energy demand for DHW $Q_{\text {water,net }}$ is estimated depending on the number of baths and sinks in the sector and on the volume of the sector.

$$
\begin{aligned}
& Q_{\text {heat }, \text { et }, m}=Q_{L, m}-\eta_{u t i l, m} *\left(Q_{s, m}+Q_{i, m}\right) \\
& \text { with }: Q_{L, m}=\left(H_{T}+H_{V}\right) *\left(18-\theta_{e, m}\right) * t_{m}
\end{aligned}
$$

\subsection{Gross energy use}

To compare the actual energy use with a theoretical figure, they need to represent the same parameter. Since the calorimeter for total heat use is installed at the collective heat distribution side of the substation of each dwelling, the net energy demands defined above need to be adjusted via system efficiencies to gross energy uses.

For $\mathrm{SH}$ an emission efficiency $\eta_{\mathrm{em}}$ and distribution efficiency $\eta_{\text {distr }}$ are added, based on the default values in the Flemish EPBD method. The latter is equal to 1, since the losses of the radiator pipes run within the protected volume and are considered as recovered. For $\eta_{\mathrm{em}}$ a value of 0,87 is assumed, as a result of the hysteresis of the thermostat, the temperature stratification in the room, etc. The net energy use for DHW is adjusted with a system efficiency of the hot water pipes $\eta_{\text {tubing, depen- }}$ ding on the pipe length. For sinks this efficiency is on average $69 \%$; for baths this is $85 \%$. All three demands in Eq. 6 include an efficiency for the heat exchanger of the substation $\eta_{\mathrm{hx}, \mathrm{combi}}$. The EPBD- methodology calculates this monthly efficiency according to Eq. 7-9, summed over all substations that are operated by the collective heat distribution system. This efficiency varies between $97,7 \%$ in winter and $93,8 \%$ in summer.

On average the net heating energy demand increases with $21 \%$ for DH IV and $17 \%$ for DH V. For DHW this is respectively with $27 \%$ and $37 \%$.

$$
\begin{aligned}
& Q_{\text {tot, }, \text { gross }}=\Sigma\left[Q_{\text {heat, net }, m} /\left(\eta_{\text {em, heat }, m} * \eta_{\text {distr, heat }, m} * \eta_{\text {hx,combi, } m}\right)\right. \\
& +Q_{\text {bath,net, } m} /\left(\eta_{\text {tubing,bath }} * \eta_{\text {hx,combi,m }}\right) \\
& \left.+Q_{\text {sink }, \text { net, } m} /\left(\eta_{\text {tubing, sink }} * \eta_{h x, \text { combi,m }}\right)\right]
\end{aligned}
$$

with : $\eta_{h x, \text { combi,m }}=Q_{\text {out }, \text { combi, } m} /\left(Q_{\text {out }, \text { combi,m }}+Q_{\text {loss }, h x, \text { combi, } m}\right)$

$$
\begin{aligned}
& \text { and : } Q_{\text {out }, \text { combi,m }}=\Sigma\left[Q_{\text {heat }, \text { net }, m} /\left(\eta_{\text {em,heat }, m} * \eta_{\text {distr,heat }, m}\right.\right. \\
& \text { * } \left.\eta_{\text {EPstor, heat }, m}\right) \\
& +Q_{\text {bath,net, } m} /\left(\eta_{\text {tubing,bath }} * \eta_{E P \text { stor,bath }}\right) \\
& \left.+Q_{\text {sink,net, } m} /\left(\eta_{\text {tubing,sink }} * \eta_{E P \text { stor, sink }}\right)\right] \text { (8) } \\
& Q_{l o s s, h x, c o m b i, m}=\Sigma Q_{l o s s, h x, m}
\end{aligned}
$$

Also the theoretical energy use needs to be normalised. The number of HDD of the reference conditions in which the theoretical performance is simulated, are determined by fitting the average of the real outside temperature of that month (from RMI data between 2001-2010) to the theoretically assumed average outside temperature, calculating the number of HDD and taking the average of those 10 years. Thus 2415 HDD are assumed, which is somewhat higher than a normal year.

\section{Actual vs. theoretical energy use}

Fig. 3 shows the actual heat uses (vertical axis) of each dwelling in function of its corresponding theoretical use (horizontal axis). In Fig. 3 (a) the actual total gross energy uses, considering both $\mathrm{SH}$ and DHW, are noticeably more dispersed than their theoretical equivalents, since the latter don't take the variation in user behaviour into account. For both projects, about half of the cases have an actual situation that is higher than what was theoretically predicted. But there are some strong outliers: only $63 \%$ of the cases are between the $50 \%$ and $200 \%$ diagonal-line.

\subsection{Domestic hot water}

\subsubsection{Comparison}

The horizontal axis in Fig. 3 (b) displays a limited range of the theoretical energy uses for DHW. After all, these values are mainly dependent of the volume of the dwellings, which are all about the same size. The figures for $\mathrm{DH} \mathrm{V}$ are somewhat higher because of their lower system efficiency.

The estimated actual energy uses for DHW are a lot lower than their theoretical prediction: most dots are below the $100 \%$ diagonal-line. Only $3 \%$ of the apartments of DH IV have an actual energy use for DHW that is higher than their theoretical value; for $85 \%$ it is even lower than half of what was predicted. For $\mathrm{DH} \mathrm{V}$ this is respectively $2 \%$ and $81 \%$. 


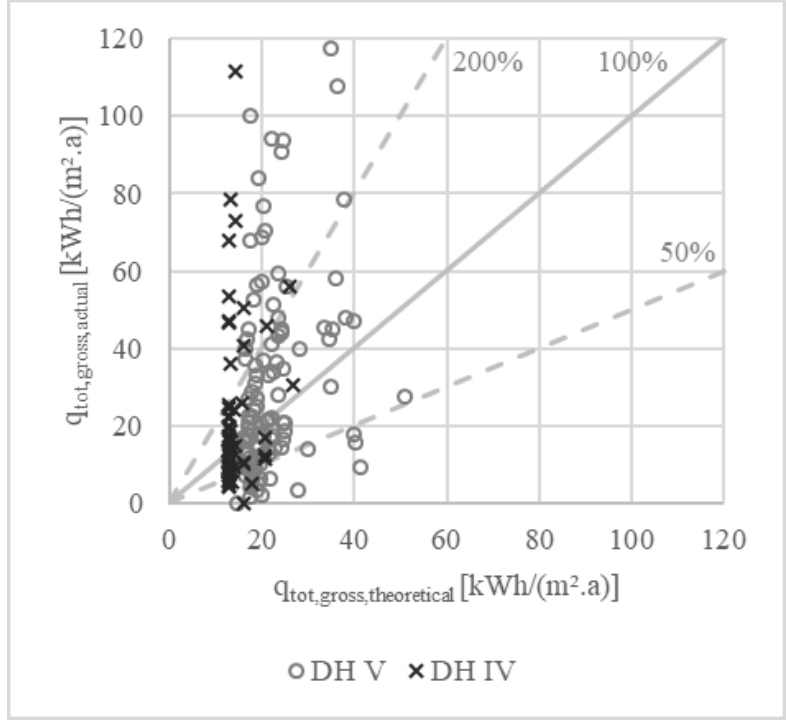

(a)

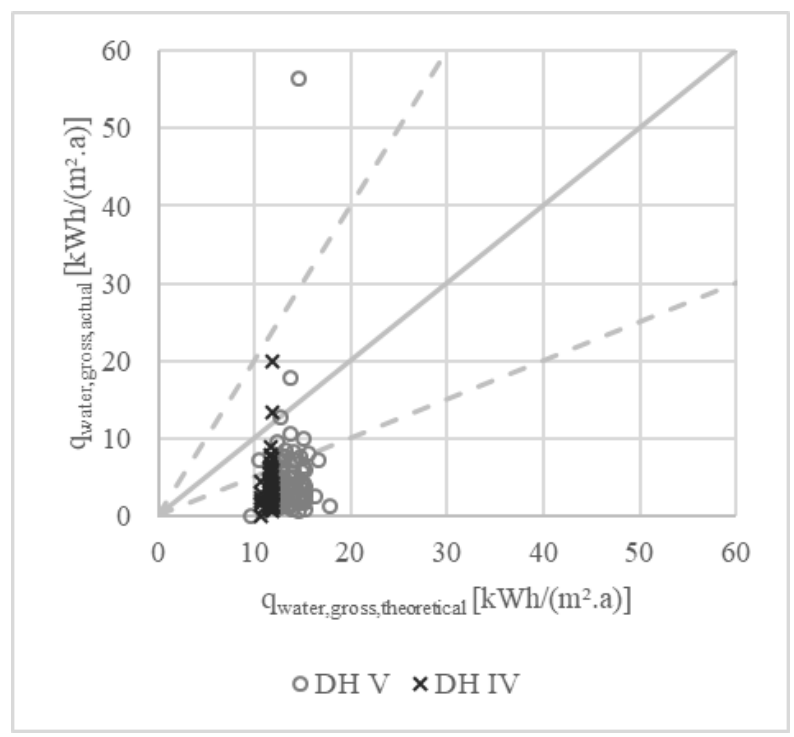

(b)

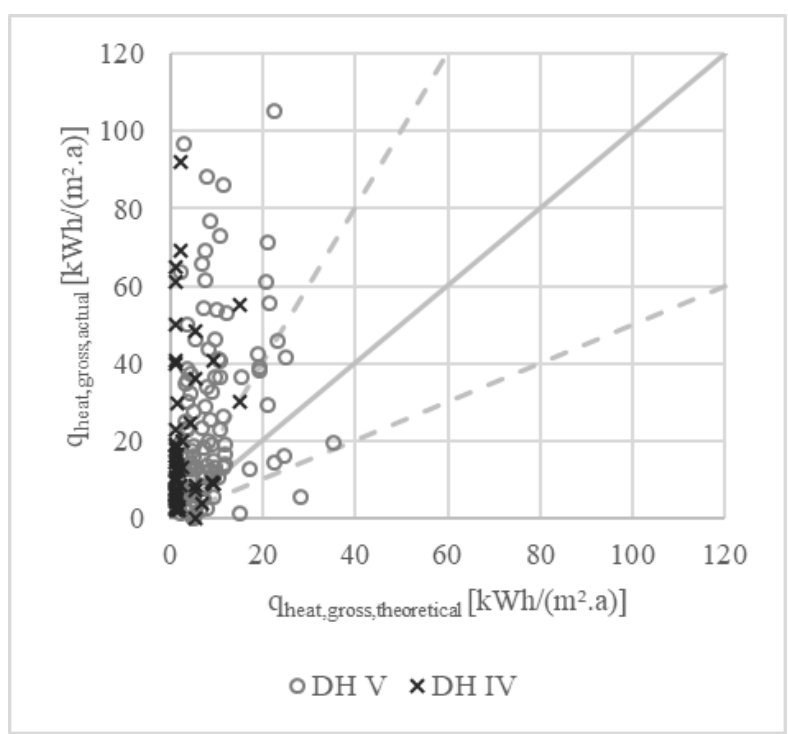

(c)

Fig. 3. Actual energy use as a function of the theoretical gross energy use in DH IV $(n=62)$ and DH V $(n=103)$ : (a) in total, (b) for DHW and (c) for SH.

\subsubsection{Occupancy}

This gap can be explained by the remarkable low occupancy of the dwellings. The apartments are designed for 2 or 3 inhabitants, but only $5 \%$ of all dwellings have a full occupation. $66 \%$ of the 157 inhabited two bedroom apartments are officialy occupied by 1 resident.

The occupant number has a dominant influence on the energy use for DHW [9]. In Fig. 4 (a) a correlation between the actual heat use for DHW and the number of residents in DH IV and V can be seen. The box plots show a higher median for $\mathrm{q}_{\text {water,actual with increasing }}$ occupancy. The outliers are a result of apartments with a a high energy use during summer months.

\subsection{Space heating}

\subsubsection{Comparison}

The theoretical values for the heating energy use, visible on the horizontal axis of Fig. 3 (c), are very similar, since their geometry and degree of insulation are similar. The outlying dots to the right represent dwellings on the groundfloor and under the roof, whose heat loss coefficient is between $43 \%$ and $170 \%$ higher than the average value for the enclosed apartments. The estimated actual energy uses for SH (vertical axis) are much more spread out. This is due to external factors (f.ex. vacant adjacent apartments or neighbours with a high set-point temperature), but even more important is the influence of the user behaviour (set-point temperature, heating duration, window opening behaviour etc.).

Most dots are above the $100 \%$ and even $200 \%$ diagonal-line. In DH IV and DH V respectively $95 \%$ and $83 \%$ have an actual energy use for SH that's higher than what was theoretically calculated. For respectively $82 \%$ and $64 \%$ qheat,actual is even more than two times as high. This is in contrast to uninsulated dwellings where a reversed prediction gap between theoretical and actual energy use is observed: there the EPBD calculation proved to strongly overestimate the energy use [10].

\subsubsection{Interior temperature}

There is an important difference between the real indoor temperature and what is theoretically considered for the heat loss calculation. The regulatory energy performance assessment method assumes one constant heating setpoint temperature of $18^{\circ} \mathrm{C}$, averaged for time and space, independent of the outside temperature or of the energy performance of the building.

An ambulant monitoring campaign was executed during winter in 12 apartments of DH IV before renovation and in 15 cases of the refurbished DH V. Fig. 5 shows the volume weighed, daily averaged temperature of the minimum, mean and maximum apartment before and after renovation. In the uninsulated situation the temperatures in the heated rooms (living room, kitchen) fluctuate strongly following a recurring pattern. In the unheated rooms (often the bedrooms) they are quite constant and very low (on average $16,7^{\circ} \mathrm{C}$ ). On the other 


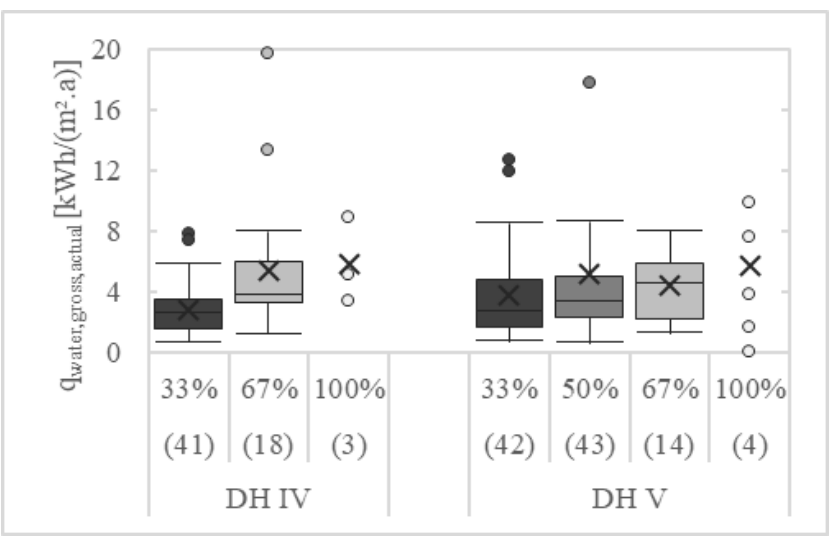

(a)

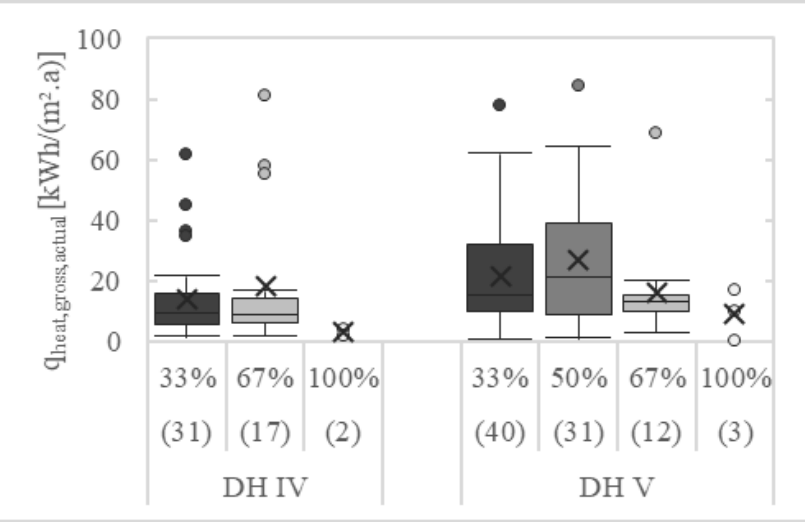

(b)

Fig. 4. Energy use for (a) domestic hot water and (b) space heating as a function of the occupancy rate of the apartments in DH IV and DH V (number of considered apartments in brackets).

hand, in the rooms of the refurbished apartments the temperatures are on average higher, particularly in the bedrooms (on average $19,4^{\circ} \mathrm{C}$ ), and more constant during the day in the heated zones. As described in literature, indoor temperatures rise after an energy efficient retrofit caused both by the changed heating preferences of the inhabitant and by physical processes, the so-called rebound and physical temperature takeback [11]. The fact that the energy performance assessment does not take into account the difference in indoor temperature between uninsulated and insulated houses explains parts of the prediction gap.

Furthermore, the temperature in the living room is often higher than the standard comfort temperature of $21^{\circ} \mathrm{C}$, especially after renovation (on average $22,0^{\circ} \mathrm{C}$ during daytime). These high set-points can be associated with the high number of eldery inhabitants, demanding higher indoor temperatures [12]. This also has an influence on the heating duration, since the day-time presence of dwellings is higher for older, retired residents [13]. In both case studies half of the residents are 73 or older. Before refurbishment there was a very similar age distribution. This actual higher indoor temperature can explain the underestimated energy use for $\mathrm{SH}$.

\subsubsection{Internal heat gains}

When comparing in Fig. 6 the theoretical heat losses $\mathrm{q}_{\mathrm{T}}$ and $\mathrm{q}_{\mathrm{v}}$ with the heat gains $\mathrm{q}_{\mathrm{i}}$ and $\mathrm{q}_{\mathrm{s}}$ of an enclosed apartment, the latter are dominant most of the year. Only during 5 months (grey background) there is a resulting net heating energy demand. This is mostly due to the large calculated internal gains, which solely depend on the volume of the dwellings. In DH IV and DH V the monthly internal heat gains $\mathrm{q}_{\mathrm{i}}$ are on average resp. 3.0 and $3.3 \mathrm{kWh} /\left(\mathrm{m}^{2}\right.$.month $)$. The actual gains are probably not as high in most apartments. A possible reason is the contemporary evolution to more energy efficient lighting and household appliances. Moreover, as this case study concerns social housing, the number of devices may not be representative of the average Flemish household.

Another influencing factor on the internal heat gains is the presence of people. Fig. 4 (b) displays the actual energy use for $\mathrm{SH}$ depending on the occupancy rate of the apartments. In order to only compare dwellings with a similar geometry, the ones with a design heat transfer coefficient by transmission of $28 \mathrm{~W} / \mathrm{K}$ or higher were excluded, just as the apartments of DH IV located above the currently vacant ground floor. A slightly downward trend is noticeable with increasing occupation. This can imply a lower energy use for space heating with a higher occupancy rate due to the increased internal gains by people and personal appliances, but the number of cases is too limited to draw conclusions.

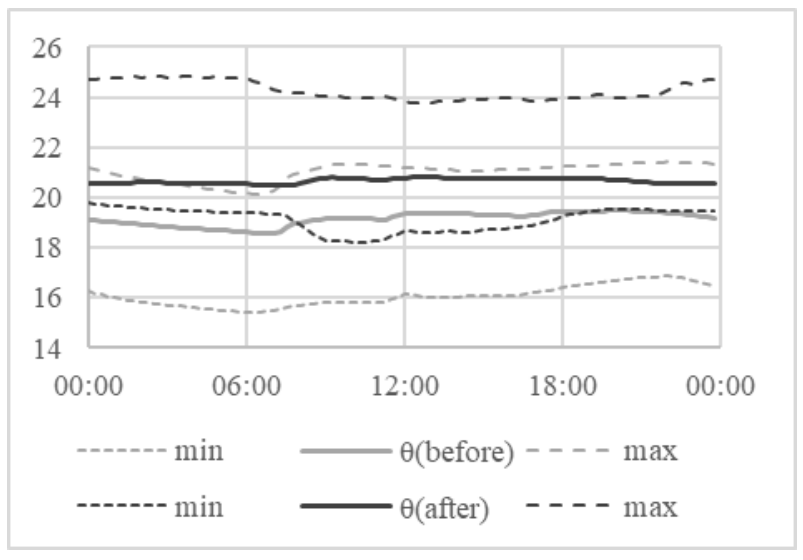

Fig. 5. Range of volume weighed daily average temperature of the whole dwelling before (DH IV) and after refurbishment (DH V).

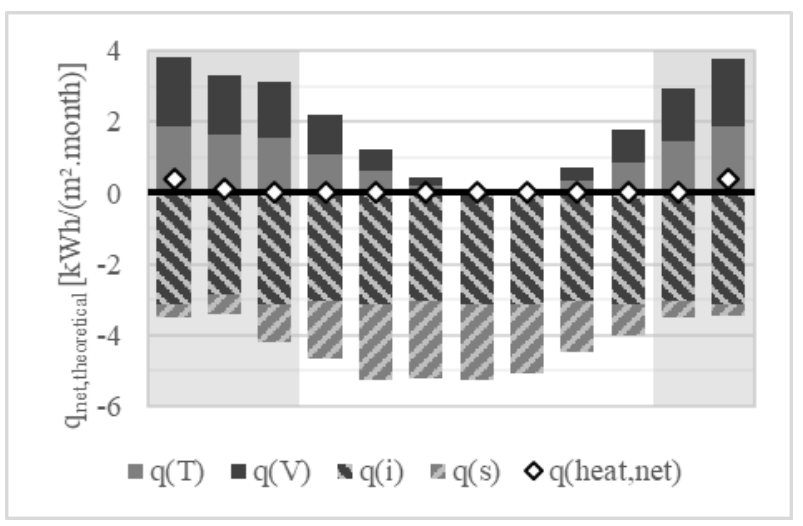

Fig. 6. Theoretical monthly heat losses (full), heat gains (hatched) and net energy demand for SH (dot) for an apartment in DH IV with qheat,net,year $=0,94 \mathrm{kWh} /\left(\mathrm{m}^{2} . \mathrm{a}\right)$. 


\section{Energy use before and after renovation}

Yearly meter readings of the original building are available for DH IV, based on the billing between 2009-2013. For DHW this is water consumption data of the collective distribution system for DHW, expressed in $\mathrm{m}^{3}$. This data is converted into energy use by assuming that the water is heated from $9,8^{\circ} \mathrm{C}[6]$ to $60^{\circ} \mathrm{C}$. For SH this is energy use data from calorimeters, expressed in MWh. The dwellings that were unoccupied, that changed tenant or that had an inconsistent meter reading were left out of account for the concerning year, just as the energy use data for SH of dwellings adjacent to a vacant apartment, since earlier research has shown that this entailed a significant increase in energy use. With the planned renovation in prospect, the number of vacant apartments increased year after year.

Since there is only annual data available, the normalisation was done using the total number of HDD of the respective year, based on data of the RMI in Uccle. To allow comparison, the same methodology was followed for the theoretical figures and the data after renovation.

In Fig. 7 the average energy use of an apartment for SH and DHW is shown before and after renovation, with the number of dwellings concerned between brackets. Comparing the average of the last 5 years before renovation with the first year of occupation (September 2018 - August 2019), the renovation reduced the heating energy use with $65 \%$, due to the low U-values and high airtightness. Surprisingly, the energy use for DHW was halved. Since the occupancy rate before renovation is barely higher, a possible cause for this finding is a wrong assumption for the temperature increase of the hot water in the unrefurbished situation. The total gross energy saving for an apartment was on average $63 \%$.

Additionally, Fig. 7 confirms the earlier identified inverse ratio between $\mathrm{SH}$ and $\mathrm{DHW}$ for the theoretical and actual situation after renovation: the theoretical prediction underestimates the heating energy use and overestimates the energy use for DHW.

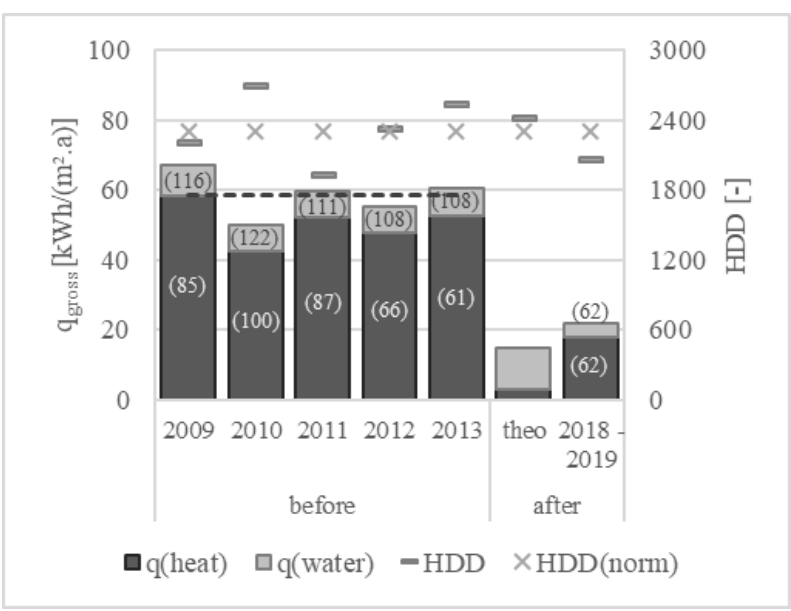

Fig. 7. Average actual energy use of an apartment of DH IV before renovation (average over the years in dotted line) and theoretical and actual energy use after renovation for SH and DHW (number of considered apartments in brackets).

\section{Conclusions}

The total energy uses for one year of several apartments in two deeply refurbished building blocks have been analysed. Although the apartments are geometrically similar, a wide variation has been identified, with some dwellings barely consuming any energy and others strongly exceeding the average. In these nZEB apartments the influence of the user behaviour appears to become dominant in relation to the building envelope performance.

Based on these total energy uses during summer months, the energy data has been categorised between $\mathrm{SH}$ and DHW. The part of the latter is found to be significantly smaller in most cases. This is not in line with the assumption, confirmed by the calculations, that the ratio of DHW in energy-efficient dwellings is becoming increasingly dominant compared to $\mathrm{SH}$. Furthermore, the actual $\mathrm{q}_{\text {water,gross }}$ is much smaller than the theoretical assumptions. The low occupancy rate of the dwellings is considered as an important cause of this.

On the other hand, the energy use for SH is strongly underestimated. $71 \%$ of all apartments have an actual $\mathrm{q}_{\text {heat,gross }}$ that is at least twice as high as their corresponding theoretical figure. This has been explained by the high internal gains and the assumed low average temperature in the theoretical calculations. An ambulant measuring campaign has shown that the average temperature in the whole dwelling increases after renovation. A certain rebound effect has been recorded: the potential energy savings are in the first place used to increase the living comfort.

These opposite findings for DHW and $\mathrm{SH}$ compensate each other somewhat which means that this contradiction can remain under the radar when only the total energy use is analysed. Therfore, it is relevant to disaggregate energy use data so that the difference between categories becomes visible.

The total gross energy uses of the dwellings in these case studies are greatly underestimated by the simplified quasi-steady state approach of the EPBD-calculation method. For DH IV the normalised actually monitored energy use for SH and DHW of the inhabited dwellings between September 2018 and August 2019 is on average $22.2 \mathrm{kWh} /\left(\mathrm{m}^{2} . \mathrm{a}\right)$, while the corresponding theoretical energy use is on average $14.1 \mathrm{kWh} /\left(\mathrm{m}^{2}\right.$.a). For DH V this is respectively 32.3 and $22.6 \mathrm{kWh} /\left(\mathrm{m}^{2} . \mathrm{a}\right)$. This observed prediction gap is in line with general findings in literature: where the theoretical calculation of limited insulated or uninsulated dwellings largely overestimates the actual annual gas consumption, it is on average underestimated in energy-efficient dwellings [14].

Although the actual energy use is higher than what was theoretically predicted, an apartment still uses on average $61 \%$ less energy for SH and DHW thanks to the refurbishment of the building block. But the reduction in energy demand associated with better building performance levels has been proved to be less than assumed.

This study was supported by the VLAIO project 'Living Labs Dwelling Renovation' (IWT/140126) and the EU Concerto initiative 'ECO-Life' (TREN/FP7EN/239497/'ECO-Life”). 


\section{References}

[1] Flemish department of environment, Voortgangsrapport Vlaams klimaatbeleidsplan 2013-2020, Luik mitigatie, pp.40-59, in Dutch (2018)

[2] Statbel, Kadastrale statistiek van het bestand van gebouwen 1995-2019, in Dutch (2019)

[3] Vlaams Kennisplatform Woningrenovatie, in Dutch, www.kennisplatform-renovatie.be

[4] E. Himpe, J. Vaillant Rebollar, A. Janssens, CONCERTO ECO-Life Deliverables, ECO-Life Monitoring Report BE 1/2 : ECO-Life Deliverable D.8.1.4. (2014)

[5] K. Ahmed, P. Pylsy, J. Kurnitski, Energy Build., Monthly domestic hot water profiles for energy calculation in Finnish apartment buildings, 97, pp.77-85 (2015)

[6] O. Gerin, B. Bleys, K. De Cuyper, CIBW Symposium, Seasonal variation of hot and cold water consumption in apartment buildings (2014)

[7] E. Himpe (supervisor: A. Janssens), doctoral dissertation, Characterisation of residential energy use for heating using smart meter data, pp.31-94 (Ghent: University, 2017)

[8] VEA, Energiebesluit - Bijlage V Bepalingsmethode van het peil van primair energieverbruik van woongebouwen, in Dutch (2014)

[9] D. Parker, Energy Build., Research highlights from a large scale residential monitoring study in a hot climate, 35, pp.863-876 (2003)

[10]M. Delghust (supervisors: Y. Deweerdt and A. Janssens), doctoral dissertation, Improving the predictive power of simplified residential space heating demand models : a field data and model driven study (Ghent: University, 2015)

[11]M. Deurinck, D. Saelens, S. Roels, Energy Build., Assessment of the physical part of the temperature takeback for residential retrofits, 52, pp.112-121 (2012)

[12] S. Wei, R. Jones, P. de Wilde, Energy Build., Driving factors for occupant-controlled space heating in residential buildings, 70, pp.36-44 (2014)

[13]E. Yamasaki, N. Tominaga, Energy Pol., Evolution of an aging society and effect on residential energy demand, 25, pp.903-912 (1997)

[14] D. Majcen (supervisors : H.J. Visscher and L.C.M. Itard), doctoral dissertation, Predicting energy consumption and savings in the housing stock (Delft University of Technology, 2016) 